\title{
Entrevista com Bárbara Dias e Wagner Maia, fundadores do coletivo Fotoguerrilha
}

\author{
Jaqueline Suarez Bastos ${ }^{1}$
}

O debate acerca de uma mídia independente ganhou novos contornos a partir das manifestações de junho de 2013 no Brasil, sendo o estopim para o surgimento e visibilidade de vários coletivos no campo da comunicação alternativa (às mídias corporativas). Conversamos com Bárbara Dias e Wagner Maia, dois dos integrantes fundadores do coletivo de mídia independente Fotoguerrilha. Professores da rede estadual de ensino, eles falam sobre o uso da fotografia (comunicação) independente na luta por direitos, especialmente, nas manifestações populares. As entrevistas, realizadas entre outubro e novembro de 2017, fazem parte de um projeto de pesquisa mais amplo, que resultou na produção do livro-reportagem Mídia e Rua: a cobertura independente das manifestações de rua no Rio de Janeiro (ainda não publicado). Violência policial, fontes alternativas de financiamento e contrainformação são alguns dos temas abordados na entrevista a seguir.

\section{Entrevistadora: Gostaria de começar perguntando sobre a relação de vocês com a fotografia, especialmente, com a cobertura de manifestações de rua.}

Bárbara Dias: Eu comecei com fotografia analógica. Na verdade, eu redescobri uma câmara que meu pai havia me dado, ele era fotógrafo e tal. Nas manifestações de 2013 eu fui como manifestante mesmo. Até cheguei a levar a câmera em um ato, mas achei muita confusão, muitos jornalistas se acotovelando... Eu falei isso é muito legal, mas eu não tenho técnica nenhuma para estar aqui. Deu confusão no dia, jogaram bomba, teve polícia e eu tinha muito medo disso tudo, muito medo de me machucar. Eu guardei a câmera nesse dia de 2013, depois fiz cursos de fotografia e retomei com essa parte mais de fotojornalismo no ano passado [2016], durante a greve dos professores. Eu comecei a fazer fotos da greve dos professores e das ocupações estudantis, porque me chamou muita atenção registrar isso de forma documental.

Wagner Maia: Em 2013 eu também estava nas manifestações como manifestante. A fotografia para mim começou durante a graduação com um amigo meu fotógrafo, que hoje é

\footnotetext{
${ }^{1}$ Mestranda no Programa de Pós-Graduação em Mídia e Cotidiano da Universidade Federal Fluminense (UFF), com bolsa pela Capes. Atualmente faz parte do Emerge - Centro de Pesquisas e Produção em Comunicação e Emergência. Pesquisa mídia independente dentro do campo da Economia Política da Comunicação, tencionando as fronteiras entre autonomia e sustentabilidade.
} 
um dos diretores do Observatório de Favelas da Maré. Eu comecei em 2014, quando consegui comprar uma câmera e atuar como amador. Depois da greve dos professores de $2016 \mathrm{eu}$ comecei a atuar na fotografia, fiz vários cursos, então eu tenho um ano e pouco na fotografia. Logo depois a gente engatou no Fotoguerrilha e desde então a gente vem fazendo fotografias de manifestações.

\section{Entrevistadora: E como essa atuação individual na fotografia se transformou em um coletivo de mídia independente?}

Bárbara Dias: Foi durante essas manifestações, nesse período de greve dos professores e ocupação escolar. Nós criamos um coletivo chamado Professores Midiativistas. Eu colocava as fotos na minha página pessoal mesmo, mas as pessoas começaram a comentar e me alertar para a criminalização que poderia ocorrer. As pessoas falavam, "melhor você criar uma página, fica mais tranquilo você postar e dá mais credibilidade também”. Criamos e no início era apenas com professores. A ideia inicial era tirar do perfil pessoal com medo da criminalização, porque a gente não fazia só foto, escrevíamos textos de críticas também. Divulgamos essa página entre os professores, a galera foi conhecendo e o negócio foi crescendo.

Wagner Maia: Nós nos conhecemos no Mendes de Moraes [Colégio Estadual na Ilha do Governador], mas a gente já se conhecia antes, porque havíamos nos visto durante a greve dos professores, que durou uns cinco meses. A gente estava na rua, ambos como fotógrafos e começamos a nos aproximar. No Mendes de Moraes ela já tinha a página dos Professores Midiativistas e me chamou: "vamos colar para fazer o coletivo só de professores?" Eu topei e engatei no coletivo.

Entrevistadora: De onde surgiu o nome Fotoguerrilha? Como que ocorreu essa transformação, saindo do perfil exclusivo de professores para o coletivo tal como ele é hoje?

Bárbara Dias: O Fotoguerrilha era um blog do Kauê Pallone, criado em 2014 durante as manifestações contra a Copa do Mundo, junto com uns amigos fotógrafos de São Paulo. No final de 2016, ele veio morar no Rio de Janeiro e a gente também esbarrou com ele na rua, fotografando... Eu e Wagner começamos a cobrir não só manifestações de professores, a questão se tornou mais ampla, fugindo do campo da Educação. Era pauta de manifestação em 
geral. A ideia de adotar um novo nome e fundir com outro coletivo abriu a possibilidade de ampliar os temas trabalhados e, também, fortalecer os dois grupos. Começamos a cobrir a greve geral, o ato da Cedae e várias outras manifestações. Depois que mudou de nome, acho até que deu mais sorte, porque ficou mais concentrado, passou a ter mais alcance, curtidas. Éramos eu, Kauê e Wagner, a princípio. Hoje tem outras pessoas que participam, mas algumas não estão muito ativas e tal.

Entrevistadora: Quando, em termos de datas, surge o perfil dos Professores Midiativistas e, depois, o Fotoguerrilha?

Wagner Maia: A greve dos professores começou em março de 2016. Como página, o perfil dos Professores Midiativistas surge em abril do mesmo ano e vai até agosto, até o final da greve. Entre setembro e outubro, o Kauê entrou em contato com a gente e nós decidimos fundir. A fusão entre Professores Midiativistas e Fotoguerrilha acontece mais ou menos nessa época. Até o início desse ano [2017], éramos apenas eu, Bárbara, Kauê e a Vanessa Ataliba, que é outra fotógrafa que fazia parte e precisou se ausentar do coletivo, por conta do trabalho e das filhas. Nós éramos o núcleo principal e, depois, no começo desse ano, entraram mais sete pessoas.

Entrevistadora: Vocês percebem alguma diferença entre a ideia de mídia alternativa e mídia independente?

Bárbara Dias: Eu prefiro o termo independente, coletivo autônomo, independente. Alternativo a gente não usa muito, não, mas eu não vejo muita diferença. Tem mídias que usam o termo independente sem ser. O pessoal do movimento, como os anarquistas e os estudantes, costuma usar mais o independente, o termo é mais usual nesses grupos com os quais a gente dialoga, como o movimento secundarista, que liderou as ocupações nas escolas. Foi muito bom estar fotografando as ocupações, nós aprendemos muito com esse processo deles. Eles sabiam mais do que a gente sobre o porquê de estar ali. Acho que o termo independente é mais por isso e, também, dizer que a gente é independente de financiamento.

Entrevistadora: Acredito que um dos grandes desafios seja manter a mobilização dos participantes no coletivo, por conta de não haver um contato constante e, especialmente, 
pela ausência de remuneração financeira. $O$ que vocês fazem para manter a motivação da equipe e o funcionamento do coletivo?

Bárbara Dias: A gente geralmente se conhece nos atos, ou quando precisa fazer alguma coisa, como a seleção das fotos para a montagem da exposição. A gente não tem uma sede, então conversamos muito por aplicativo. Hoje tem ato tal, quem pode ir? Vou eu e mais sei lá quem. A gente se encontra no ato, faz as fotos, chega em casa e publica.

Wagner Maia: Eu acho que é comum em muitos coletivos uma caída, até porque a gente mantém outra vida para além da fotografia independente. Você precisa sobreviver, fazer faculdade, trabalhar... Para o Fotoguerrilha, 2016 foi um ano que teve muitos protestos, nesse sentido, foi uma forma de manter o coletivo mais unido, toda semana a gente estava se encontrando, fazendo fotografia de protesto, se reunindo. Quando no final de 2016, início de 2017, os protestos foram diminuindo, a gente percebeu que a galera foi se distanciando, não se via mais, então há uma dificuldade de se manter e de se encontrar. Nos últimos três meses, a gente conseguiu fazer umas três ou quatro reuniões, inclusive em uma delas surgiu a ideia da exposição Rio de Caos, que foi totalmente organizada através de Skype. Mas eu acho que tem uma dificuldade muito grande para o movimento independente se manter. Primeiro, nós não queremos financiamento de empresa nenhuma e ninguém para mandar no nosso coletivo. Segundo, é muito difícil para a gente angariar verba para um projeto autoral e, assim, a gente quer muito uma coisa coletiva. Então, nas exposições, por exemplo, nós levamos uma caixinha solidária. A gente está pensando em fazer isso, porque existem vários lugares que estão chamando a gente para apresentar a exposição. Fizemos uma conta na Caixa Econômica para gente mesmo se autofinanciar. Foi com esse dinheiro que a gente conseguiu arcar com as impressões das fotografias que compõem a exposição, que, ao todo, custaram quase $R \$ 400$. Para a gente que é uma mídia independente, de professores do Estado, jornalistas... Há uma dificuldade muito grande de se manter enquanto coletivo, então a gente tenta dessa forma, através do somatório de caixinha, de projeto pra poder angariar recurso, de pessoas que podem financiar pela internet e do autofinanciamento. É dessa forma que a gente está conseguindo levar o coletivo para a frente.

Entrevistadora: Vocês, enquanto coletivo, pensam em buscar algum meio externo para financiar o funcionamento do próprio Fotoguerrilha ou de projetos específicos, como a produção de documentários, por exemplo? 
Bárbara Dias: A gente já pensou em fazer um financiamento coletivo, com as pessoas que gostam do Fotoguerrilha, mas lançar por alguma causa específica. Talvez uma nova exposição, com um material melhor, mais bem acabado, por exemplo. Ou talvez através da venda de algumas fotos nossas, por meio de uma colaboração solidária, ou seja, você paga o quanto achar que vale, sabe? Realmente indivíduos e não corporações, mas acabou que nunca colocamos isso em prática, não. Para a exposição, a gente orçou tudo, tinta, passagem, gasolina... E dividiu entre o próprio grupo.

\section{Entrevistadora: Como vocês lidam com o pessoal que participa da ação direta durante os protestos? Há fotografias que captam o momento exato de uma explosão ou confronto. Qual o segredo para conseguir esses registros?}

Bárbara Dias: Não que a gente tenha essa intenção, mas a gente já fica próximo deles porque sabemos que são as pessoas em potencial que farão algo. Então, quando a gente vê aquela galera, a gente sabe o que eles podem ou não fazer. Se os meninos estão com o rosto coberto perto de um banco; se um já tacou uma pedra, eu já sei o que eles vão fazer e eu já me posiciono perto dessas pessoas. Nunca influenciamos, eles fazem o que eles querem e nós estamos lá para fotografar. Nós estamos, geralmente, muito perto, porque a gente sabe quem são eles. A vivência faz a gente saber quem são, mesmo sem a máscara a gente consegue ter uma noção. É muito importante frisar que a gente nunca expõe o ativista sem a máscara, até para não criminalizá-lo. Nunca colocamos a foto com o rosto. Ou embaçamos, ou perdemos a foto. Ninguém do nosso coletivo faz isso.

Wagner Maia: Em algumas fotografias até aparece, mas a gente fala com a pessoa. Ainda assim, geralmente, a gente não coloca. Eu tenho uma teoria que diz que a fotografia é a soma das perdas. A gente analisa tudo isso na fotografia. Quando o protesto está rolando, acontecem várias coisas ao mesmo tempo: confronto, bombas... Onde você pode estar que, possivelmente, o bicho vai pegar? Próximo à vidraçaria vai pegar, perto dos policiais, próximo dos moleques da ação direta e por aí vai. O segredo do fotógrafo é saber isso, esse é o time que precisa para você fazer uma fotografia interessante como a nossa. A gente procura sempre estar de um lado e o nosso é sempre à esquerda, quase no final da esquerda.

Entrevistadora: Os protestos no Rio têm terminado, corriqueiramente, em conflitos. Vocês já sofreram ou têm medo de sofrer algum tipo de violência durante a cobertura? 
Bárbara Dias: Em 2013, quando eu participei como manifestante, eu tinha muito medo, se estourava uma bomba, eu corria para longe. Hoje em dia, se rola pancadaria eu estou correndo para perto. Mas isso foi um processo, um processo de criar essa coragem e ver que a foto é importante de fazer, além da questão do equipamento de segurança, também. Eu uso capacete e máscara, porque eu sofro muito com o gás. Pedrada eu nunca levei, mas bala de borracha sim, na barriga. Eu estava com o capacete que uso escrito "imprensa", estava fazendo fotos da tropa de choque de perto e eles atiraram uma bomba de gás no nosso pé. A gente falou que era da imprensa e aí piorou: eles armaram a escopeta doze e só deu tempo de correr, mas quando eu fui correr, virei para ver e tomei um tiro de raspão na barriga. Foi de raspão e doeu para caramba.

Wagner Maia: A questão é que você só faz foto se estiver muito perto, porque é quando você está muito próximo que a fotografia sai boa. Então, você vai estar sujeito a levar uma pancada, a levar uma pedrada e, inclusive, ser mal interpretado pelos movimentos sociais. Quando eu comecei a fotografar a greve dos professores, houve um episódio em que fui cercado por cinco ou seis caras, me apresentei como professor e fotógrafo, e falei que estava do lado deles.

\section{Entrevistadora: A que você atribui essa violência exacerbada por parte da polícia em relação à mídia?}

Bárbara Dias: Eles não gostam da gente. Fazem um monte de coisa errada e sabem que vamos filmar e denunciar. Eles não se sentem à vontade para serem truculentos. Eles continuam sendo, a postura deles não muda porque a gente está ali, mas agora eles sabem que nós vamos estar filmando, fotografando e jogando todas essas arbitrariedades para todo mundo ver, principalmente, a mídia independente. A gente realmente tem esse objetivo, de mostrar como eles agem, é uma denúncia mesmo. Um dos focos do Fotoguerrilha é denunciar a violência policial. A gente pensa que, se eles fazem isso com aquele tanto de câmera em cima deles, o que eles fazem na favela quando não tem ninguém olhando?

\section{Entrevistadora: Nesse tempo fotografando, especialmente, as manifestações, houve algum ato que te marcou, seja pela importância ou até pela violência?}

Bárbara Dias: Quando eu comecei a fazer as fotos, eu não tinha máscara, nenhum equipamento no geral. A primeira vez que fui exposta ao gás lacrimogêneo foi sinistro, é 
muito difícil fazer foto com esse gás todo no rosto. Depois disso, eu fui comprando máscara e me equipando melhor, mas também não adianta muito, não, porque tem que ser uma máscara muito boa para segurar o impacto, ou mesmo o gás. Para fazer uma foto boa, precisa chegar perto. As manifestações dos professores foi uma greve muito combativa, então quando começou a ter a repressão policial me marcou muito, porque eu comecei a ver a polícia, como ela atua na prática. Quando você está muito perto, você realmente vê. Vi um professor levar com o cassetete na cabeça uma vez, abriu a cabeça dele. E a polícia realmente deu de propósito, porque o professor passou ao lado do policial. Eu estava do lado desse professor, podia ter pegado em mim. Eu me lembro até hoje do barulho do cassetete batendo na cabeça dele. Eu fiz uma foto desse professor que foi bem compartilhada, até. Eu não fiz para expor ele, mas eu achei que precisava compartilhar aquilo ali. Esse dia foi bem marcante. Tudo isso foi um processo, essa questão de você estar no ato fazendo foto dessa violência toda, você vai aprendendo a fazer esse tipo de fotos. Com o tempo, você vai chegando mais perto, sabendo onde pode chegar e onde não pode, e isso é um aprendizado. Tem menos de dois anos que eu faço isso e eu já consigo me posicionar melhor, mas isso é prática. Quanto mais violento, mais você aprende. Parece que você fica com o alerta ligado.

\section{Entrevistadora: Algo que me chama atenção é a pouca presença de mulheres na cobertura dos atos. Você sente que existe alguma relação entre a violência dos protestos e essa ausência? Como mulher e midiativista, o que acha disso?}

Bárbara Dias: A questão do machismo é sempre presente. Em relação à violência policial, eu não vejo a polícia amenizando por eu ser mulher. Quando ele tiver que gritar, ele vai gritar, vai me xingar e, se tiver que tacar bomba do meu lado, vai tacar. Eu vejo um pouco mais de problema nos demais fotógrafos. Eles olham para a gente subestimando um pouco, meio desacreditando que nós vamos fazer aquilo. No protesto passado, tinha um fotógrafo do meu lado e ele meio que colocou o braço na minha frente quando a polícia começou a jogar bombas. Ele fez algo do tipo, "vou te proteger". Eu cutuquei o ombro dele e falei: "está tranquilo, eu não preciso da sua proteção, não preciso da proteção de ninguém”. Se eu me machucar alguém vai me ajudar e tudo bem, mas nessa dele me "proteger", ele me atrapalha. Eu estou querendo fazer a foto e o cara me segurando. Eu acredito que ele tenha pensado, "ela é uma mulher, é mais vulnerável". Também tem aquele negócio do "toma cuidado", alguns falam, mas eu não dou muita ideia, não. Esse cara, fazendo isso no ato passado, foi muito engraçado. Eu toda equipada, igual a ele, se tiver que levar porrada, eu vou tomar junto com 
ele, provavelmente. Em relação às mulheres, eu vejo muito poucas mulheres ainda, principalmente, no front mesmo. Você tem que perder muito esse medo e a sociedade impõe muito que a mulher seja delicada, que tem que se preservar. Eu acho que essa pressão social influencia a mulher a não se sentir capaz de estar ali no front, fazendo a foto. Eu vejo mulheres que são ótimas fotojornalistas, mas são bem poucas. No geral são homens.

\section{Entrevistadora: Qual a área de interesse do Fotoguerrilha para além de manifestações de rua?}

Bárbara Dias: O nosso coletivo é mais centrado em protestos, mesmo, mas a gente tem criado umas pautas alternativas, como ocupação, por exemplo. A gente acha interessante e a galera curte. Fizemos uma no Centro, próximo à Carioca e só tinha a gente de mídia. Era um pessoal em situação de rua, ambulantes... Era uma ocupação por moradia em um prédio da Prefeitura do Rio. A polícia chegou ao local armada ostensivamente. É um tipo de matéria muito importante. $\mathrm{O}$ nome Fotoguerrilha sugere coisas ligadas à manifestação, ao meio urbano... A guerrilha simboliza um pouco dessa resistência, de você estar fazendo uma foto e realmente resistir, sem recurso, sem grana, como o cinema de guerrilha, no improviso, com equipamento ferrado. A gente não tem dinheiro para comprar máquinas boas, isso é uma guerrilha! Resistir, fotografar as manifestações e levar narrativas independentes, ampliar a voz de grupos quase nunca ouvidos.

Entrevistadora: Antes de começarem a fotografar manifestações, vocês procuraram saber ou ler a respeito de jornalismo de guerra, como se portar no meio de confrontos? Vocês hoje tomam alguma medida de segurança?

Bárbara Dias: No início, nada, a gente só viu que precisava de capacete porque 'voava' muita pedra e a gente podia se machucar a qualquer momento. Às vezes, a gente fica no meio, entre a polícia e o manifestante. Os manifestantes não querem acertar a gente, sabemos, mas, às vezes, acertam porque não têm mira. E a polícia também, ora quer acertar, ora quer acertar novamente (risos). Eu aprendi muito na marra, me machucando, às vezes. A gente não recomenda a pessoa ir sozinha, sem ter alguém por perto. Vamos? Vamos juntos. No nosso coletivo nós temos, hoje, alguns protocolos. A gente tenta andar em dupla, mas é aquela coisa, quando estoura a bomba, cada um corre para um lado para se preservar. Mas, para cobrir, a gente tenta estar junto. 
Wagner Maia: Mas também há uma diferença entre o fotógrafo e o manifestante. Quando estoura uma bomba, o manifestante corre para se defender, já a gente procura correr para ter um ponto fotográfico e isso faz toda a diferença. O ponto fotográfico, às vezes, é ao lado da bomba. A gente corre para bomba, para o policial. Nas últimas manifestações da Alerj [Assembleia Legislativa do Estado do Rio de Janeiro], por exemplo, eu estava distante de onde começou a guerra, mas quando estourou eu corri para a guerra. Isso é insano, nós vamos para cima da ação. Esses protocolos de segurança, como ter a carteirinha da Fenaj [Federação Nacional dos Jornalistas], são muito importantes, mas não ajudam tanto o fotojornalista quando ele está exposto. Nós temos o nosso próprio protocolo. A gente tem o que fazer, tem que ficar perto do ato, mas distante a ponto de se proteger. Eu vou ficar muito próximo, mas atrás de uma árvore, por exemplo, que vai me proteger de uma bala de borracha ou de uma bomba. Eu acho, inclusive, que esses manuais pecam, pecam por não distinguirem um manifestante de um fotógrafo. A gente vai chegar o mais perto possível, mas, se a gente seguisse o manual, isso estaria errado, porque é perigoso. Pra gente, eu acho que vale mais a pena olhar cientificamente e fazer um roteiro nosso, do Fotoguerrilha. 